\title{
LOS MUEBLES CON SECRETO: ESCONDER, EXHIBIR, APRENDER
}

\author{
MÓNICA PIERA MIQUEL \\ Asociación para el Estudio del Mueble
}

Fecha de recepción: enero 2012

Fecha de aceptación: febrero 2012

Entre los pecados capitales se cuenta la avaricia, que se define como el afán excesivo de adquirir y poseer riquezas. Pecado que, enumerado por Gregorio I, priva al hombre de la gracia y le hace digno de la pena eterna. Pero no por ser considerado un vicio se encuentra poco extendido entre los hombres de todas las épocas. La avaricia es perniciosa porque estropea las relaciones, dificulta la confianza, lleva a desigualdades y perturba el equilibrio y la paz social ${ }^{1}$.

La avaricia es el grado máximo y nefasto del sentimiento de posesión y es considerado como un desequilibrio, pero en grados inferiores la necesidad de posesión no sólo no es mala, sino que la sociedad la aplaude y la reconoce como positiva. La avaricia es el exceso de un instinto innato en el hombre, el de acumular en época de bonanza por si llegan tiempos duros, difíciles y de escasez. Es, por tanto, la desmesura de un movimiento del ánimo necesario para la supervivencia. Así, ahorrar, guardar, proteger o cuidar son acciones consideradas virtuosas y útiles para la vida, que parten de esta necesidad de poseer y recoger. Se aprecia a la persona que las lleva a cabo, ya que bien gestionadas aportan bienestar y seguridad.

En los niveles pecaminosos o en los virtuosos, todas estas acciones requieren de «algo», de un objeto u objetos que son el motivo de la acción. Es cierto que el hombre

1. De las muchas obras de arte que representan los pecados capitales, destacamos la excelente pintura $L a$ Bruja del siempre satírico Pieter Brueghel el Viejo. Protagoniza la escena la avaricia bajo la apariencia de una mujer que, con coraza y casco para protegerse, huye de la devastación con un cofrecillo bajo el brazo. (Dulle Greit, 1562, Museo Mayer van den Bergh, Amberes) Su autor sigue directamente la estela de la pintura de carácter moralizante de El Bosco, como en Mesa de los pecados capitales, 1485, Museo del Prado, Madrid. 
puede guardar cosas inmateriales, como los secretos que se le comunican con la intención de que no se revelen, pero el tema que motiva este escrito responde a cosas materiales, y en concreto a dinero, joyas, documentos, metales nobles, piedras preciosas y simipreciosas, así como a bienes inusuales, exóticos y escasos, todos ellos objetos de valor codiciados por hombres de todos los tiempos. Estos bienes preciados, habituales componentes de los muchos tesoros escondidos a lo largo y ancho del planeta, han requerido de un espacio donde custodiarse en secreto, para lo cual se han diseñado infinidad de contenedores. Se han escondido o se han exhibido, pero siempre bajo medidas de seguridad que preservaran su integridad y evitaran la sustracción. Es interesante esta dicotomía, que ha incidido directamente en el diseño de muchos de estos contenedores: el hombre ha tenido necesidad de asegurar la posesión de los objetos caros y deseados, pero igualmente ha sentido el deseo de exhibirlos para hacer visible el éxito de su posesión y poderlo compartir.

Si centramos nuestra atención en los contenedores para tesoros -excepcionales o comunes-que han formado parte del mobiliario de uso doméstico en España durante la Edad Moderna ${ }^{2}$ comprobamos esta dualidad de intereses y cómo el deseo de enseñar el «tesoro» acabó revirtiendo en una demostración de los gustos y riquezas y también del nivel cultural del propietario. Naturalmente este tema refiere a pocos sujetos, ya que estamos hablando de una pequeña minoría de la población que era aquella que tenía el privilegio de acumular y disfrutar de bienes suntuosos y de valor económico ${ }^{3}$. De todas formas, los documentos, especialmente los inventarios, nos revelan que muchos de los que se esmeraron en proteger sus propiedades eran personas con capacidad adquisitiva limitada, y que en realidad aquello que tan ansiosamente protegían eran bienes relativamente poco importantes, aunque para ellos supusiera todo lo que habían conseguido agrupar.

La primera función que debían cumplir los contenedores destinados a objetos de valor era la de poner a buen recaudo. Por ello, con el fin de evitar robos y pérdidas se desarrollaron muebles de guardar para el transporte, es decir que permitían el desplazamiento del tesoro con seguridad, y, por otro lado, contenedores para dejar fijos en los interiores. Teniendo en cuenta que los muebles eran escasos y caros, y los de seguridad todavía más, muy a menudo en la Edad Media y en la Edad Moderna, el mismo mueble podía servir para ambas funciones. Es decir, que se desarrollaron tipologías que fueran fácilmente transportables, pero que en la casa cumplieran también su función. Aunque el ingenio y la necesidad permitieron que un calcetín o una pechera pudieran servir a tal

2. Tratamos aquí únicamente los contenedores del ámbito privado, dejando para otra ocasión el amplio apartado de los ideados para instituciones, entidades bancarias, iglesias u otras entidades colectivas.

3. La gran mayoría de la población estaba alejada de poder disfrutar de bienes de los que trataremos aquí, especialmente en el ámbito rural. Como comenta Pounds en el ámbito rural las gentes «tenían casas con una puerta - a veces dos- que no podían cerrarse con total seguridad, y unas ventanas que, en el mejor de los casos, se cerraban con postigos. Era fácil entrar en ellas, y los robos eran frecuentes PounDS, N. J. G., Historia de la vida cotidiana, Barcelona, 1999, p. 246. 
efecto, la industria de la madera y sobre todo la del hierro se puso con éxito al servicio de la custodia de estos grandes o pequeños tesoros.

Han llegado hasta nosotros ejemplares de lo que podríamos llamar «cajas fuertes» de uso cotidiano de finales de la Edad Media, pero sobre todo del siglo XVI, que responden a unos modelos repetidos. Se presentan en forma de cofres o cofrecillos, pero la parte más importante de la pieza y la que diferencia este contenedor de otros era el sistema de cierre que siempre incluía una cerradura o un candado ${ }^{4}$. El modelo de cerradura con guardas de época romana, que impedían el paso de toda llave que no fuera la correspondiente, siguió utilizándose hasta el siglo XVIII, pero los avances de la industria de la forja a partir del siglo XIV permitieron piezas más precisas. De todas formas, fue en el siglo XVI cuando se crearon modelos más complicados con resortes, ballestas y pestillos que se articulaban en un engranaje realmente difícil de entender, pero que accionado por una simple llave cerraba el mueble y protegía su contenido.

Los cofres medievales solían tener un alma de madera que se cubría por la cara exterior con algún tipo de piel, ya fuera curtida, cruda o de pergamino. Como la piel es un material flexible se adaptaba con facilidad a las formas de las cajas. El encorado daba solidez, hacía la función de aislante de la temperatura y era impermeable si se engrasaba bien, de tal manera que ayudado de una tapa convexa evitaba que el agua penetrara en el interior. A menudo, especialmente en ejemplares del siglo XIV, el interior se forraba de pergamino con una cola de colágeno que le añadía resistencia. Flejes y cantoneras aseguradas por clavos reforzaban la estructura y evitaban que se rompiera el mueble si recibía golpes o caídas. Muchas veces se colocaban las bandas del barreado muy juntas unas de las otras con el objetivo de evitar que algún indeseado intentara acceder al interior traspasando la madera. Estos muebles de portar suelen responder a estructuras pesadas y llevan siempre asas que ayudaban a su traslado. Para asegurar las arcas y los cofres sobre los animales de carga o sobre los carros, se les podía añadir hebillas en alguna de las caras por donde hacer pasar las correas de fijación.

Las arcas a tal uso podían tener diferentes medidas, pero algunas de ellas eran lo suficientemente grandes como para que en su interior cupieran diferentes cofres y maletas que repartían las pertenencias de un propietario. Además, en los mejores ejemplares era posible que las arcas más grandes dispusieran de cajones, compartimentos o tabicas donde fijar los diferentes contenedores más pequeños que se colocaban en el interior. Así se podía separar la caja de ropa blanca, de la de color o ésta de las armas. En compartimentos más pequeños se colocaban las arquetas para joyas o también los objetos de plata, las especies o los confites, de manera que todo pudiera ser bien trasladado sin mezclarse ni recibir golpes ${ }^{5}$. Era el propietario o propietaria quien vigilaba personalmente la llave, que muchas veces se colgaba del cuello o se ataba al cinto. Isabel de Castilla guardaba las suyas y a su muerte «abrieron ciertas arcas de

4. Ibidem, p. 247.

5. Depring, G. B., Réglements sur les arts et métiers de Paris, rédigés au XIIle siècle, et connus sous le nom de Livre des Métiers d'Étienne Boileau, Paris, 1837. 
las quales la Reyna Nuestra Señora tenía las llaves y en una dellas hallaron las llaves siguientes... $\rangle^{6}$, entre ellas unas barradas, otras guarnecidas de cuero, otras muchas con cajones y alguna que dentro tenía una arquilla.

Entre los contenedores de transporte destacaban los «cofres de Flandes» de gran finura en las filigranas de hierro y en las decoraciones de la piel, que incluso podía presentarse dorada. Respecto a los de pequeñas dimensiones gozaron de gran demanda los portacartas, especialmente durante el siglo XV y principios del siglo XVI. De unos $16-18 \mathrm{~cm}$. de largo, abrían por su lado corto y presentaban una estructura de madera forrada por el exterior con piel, cubierta en su totalidad por una guarnición de hierro a la manera de malla rígida. Se recogen citados como coffrets à la manière d'Espagne y su éxito permite poder hablar de una vasta producción castellana, pero también flamenca y francesa. Su expansión por el continente fue considerable, a juzgar por los ejemplares conservados y los documentados, y es que era un mueble que respondía muy bien a las necesidades de la época: era seguro, resistente y con una decoración a la moda que permitía lucirlo sobre las mesas de los estudios. Además, en los lados incluía unas anillas por las que se pasaba una cuerda que permitían llevarlo colgado en el cinto, los hombros o en el animal de carga. Tradicionalmente se conocían estas piezas como portamisales ${ }^{7}$, pero las últimas investigaciones han permitido relacionarlas con lo que en la documentación se recoge como portacartas que servían para guardar y transportar documentos, libros y cartas, pero también joyas y pequeños objetos de valor, además de los textos religiosos ${ }^{8}$. Así, esos diferentes usos se suman al de estuche de libros de horas, que efectivamente se describe en las cuentas de Isabel de Castilla

«mandó hacer su Alteza una arquilla para poner las Oras de rezar., que costó la madera 62mrs. más una vara de terciopelo carmesí para cubrirla, 2.600 mrs. una tercia de grana para forrarla, 500mrs. barras y cerraduras de hierro, 1095 mrs. cerradura 930 mrs. y por la clavazón dorada 150 mrs, 315 por forrarle y guarnecerle y 200 mrs. por una bolsa de cuero para meterle dentro»" ${ }^{9}$.

La mejora en las técnicas de obtención y trabajo del hierro y del acero facilitó que ya desde la Baja Edad Media se construyeran cofres, cofrecillos y portacartas totalmente en hierro, a base de láminas gruesas soldadas que evitaban el armazón de madera, y que realmente podemos considerarlas cajas fuertes o de caudales. Se conseguía, de esta

6. TORre, A. de la, Testamentaria de Isabel la Católica, Vallalodid, 1968.

7. Entre los muchos ejemplos que podríamos citar, escogemos una publicación de 1924, ALLEMAGNE, H. R. de, Musée le Secq des Tournelles a Rouen. Ferronnerie Ancienn, París,1924, lám. CCCXCVII, que evidencia el protagonismo de los objetos artísticos de hierro en colecciones de principios de siglo XX, siendo la primera colección documentada la de Frédéric Spitzer (Viena 1815-1890) todavía en el siglo anterior. ElVIRA, L., «El col·leccionisme del ferro. Apunts per a una història», en L'art del ferro. Rusiñol i el col-leccionisme del seu temps, Sitges, 2007.

8. Félix de la Fuente ofrece esta nueva lectura de los portamisales. Sofía Rodriguez Bernis, en la misma publicación ratifica esta denominación y añade que son piezas para el traslado de documentos, pero también de todo tipo de objeto de valor. (Catàleg de mobles del Museu Frederic Marès, en prensa)

9. AguiLÓ, M.P., El mueble en España. Siglos XVI-XVII, Madrid, 1993, p. 93. 
manera, un mueble totalmente rígido y fuerte cuya estructura se acompañaba, a menudo, de cerraduras con sistemas que podríamos llamar de engaño, ya que se diseñaban para dificultar la localización de la bocallave y hacían compleja su apertura ${ }^{10}$. Entre estas producciones destacan sin duda las aportaciones de los armeros de Alemania, especialmente de Nuremberg y Augsburgo, quienes además de las valoradas armaduras, construían las mejores cajas de caudales, grandes y pequeñas, y los muy complejos cierres de precisión. Estas cajas eran muy útiles para un gran número de profesionales y para la ascendiente burguesía alemana y del resto de Europea, por lo que de inmediato se exportaron, conociéndose en Francia como «coffre-fort d'Allemagne» y en el Reino Unido como «Armada chests». Estos cofres «en España eran muy estimados, de ello dan fe los 250 ducados en que se tasaron en 1570 unos cofres

«de yerro del tamaño de escriptorios, barreados con barras de yerro y las cerraduras en el cobertor por la parte de dentro y la llave por de fuera y muchos pestillos traídos de Alemanía» ${ }^{11}$.

El hecho de que comercializaran a través de las ferias, como la Medina del Campo, permite entender que se hayan localizado entre las pertenencias de comerciantes y financieros, como es el caso del inventario post mortem de Simón Ruiz, de la segunda mitad del siglo XVI ${ }^{12}$.

Pero éstos no eran únicamente muebles para el traslado de bienes, sino que también se lucían en las casas, como testimonian las variadas decoraciones que los enriquecen. Efectivamente, los mejores ejemplares se decoraban con grabados al ácido, con hojas de hierro superpuestas o con policromías de temática floral, festiva o imperial, siguiendo grabados a la moda, como los producidos por artistas del nivel de Jost Amman, Virgil Solis, Niklas Stoer o Erhard Schoen. A partir del análisis de la iconografía, M. Paz Aguiló sugiere, incluso, que algunos de ellos pudieran formar parte de los regalos de esponsales, situando estos cofrecillos de hierro o acero en la misma categoría y con el mismo valor simbólico dentro de la familia alemana ${ }^{13}$, que habían tenido un siglo antes las arquetas en marfil y hueso tipo Embriacchi en la Península italiana y en el resto del Mediterráneo, o las amatorias trabajadas en pastiglia en Cataluña

10. Un cofrecillo de este tipo se localiza, por ejemplo, en la colección del Museu Frederic Marès (MFM 1890) y otro muy similar en la Fundación March de Palma. En ambos casos, el diseño de la cerradura se repite en la parte posterior del mueble, de tal manera que es difícil saber cual de los dos lados abre. Igualmente, las cajas de caudales alemanas del siglo XVI suelen incluir una cerradura de engaño en el frente de la caja, mientras que la que realmente abre es la situada en el centro de la tapa, oculta bajo una tapeta.

11. Marcos, M. A., «Arca de caudales», en Museo Nacional Colegio de San Gregorio: colección / collection, Madrid, 2009, pp. 138-139.

12. Actualmente en las colecciones del Museo de las Ferias de Medina del Campo.

13. AguiLó, M. P., «Arquetas alemanas de hierro, joyeros o cajas fuerte», en Estudio del Mueble, n 13,2011 , p. $10-13$. 
y Valencia ${ }^{14}$. Como comenta esta historiadora, en las arquetas de hierro alemanas se guardaban joyas, objetos preciosos de pequeño tamaño, se utilizaron para documentos, cartas y dinero, aprovechando la producción de calidad de los talleres de metal locales para realizar un estuche de lujo, que rápidamente fue admirado y demandado en toda Europa. Alemanas, italianas, flamencas o españolas, las arquetas y los cofrecillos gozaban de buena reputación si estaban bien trabajadas y se construían con materiales y técnicas bien consideradas. Su uso como objeto de valor social se confirma cuando analizamos los bienes de los inventarios reales. Así, entre los de doña Juana, además de ocho camas, seis mesas y tres braseros, destaca un elevado número de cofrecillos portacartas de marfil, de terciopelo y de hierro, además de varios cofres de Flandes ${ }^{15}$.

Cofres, baúles y arcas, de tamaño grande o pequeño, consiguieron perdurar a lo largo de los siglos como las tipologías más demandadas para el traslado y la guarda de bienes de valor. Las características desarrolladas desde la Edad Media se mantuvieron y mejoraron, solucionando una y otra vez las necesidades de la población europea. Es así que localizamos baúles y cofres de épocas muy posteriores que mantienen las características básicas de estos ejemplares medievales y renacentistas a pesar del tiempo transcurrido. Se ahorraba en materiales y decoración para poder acceder a clientes de clase media y aumentar la producción, pero la esencia se conservó. En lugar de barreados se tendió a fijar las pieles mayoritariamente con tachuelas y clavazones sencillos, y en el caso de utilizar flejes, éstos se hacían lisos, sin las bellas tracerías medievales. La madera, la piel y el metal siguieron como materiales preferentes para construir estos muebles de guarda y transporte. Incluso llegados al siglo XIX, es fácil encontrar baúles con armazón de madera recubiertos de piel fijada por clavos de metal y cerrados por una o varias cerraduras, y escondrijos en su interior de difícil localización para preservar en la intimidad unas monedas, una joya o esa estimada carta de amor.

\section{DEL ESCRITORIO PRIVADO AL ESCRITORIO DE USO SOCIAL}

Ahora bien, en el siglo XVI se desarrolló una nueva tipología de mueble pensada especialmente para la guarda de documentos, dinero y objetos de valor. Se trata del escritorio, mueble fundamental en los interiores españoles de los siglos XVI y XVII. Su presencia aumentó a lo largo de esos dos siglos ya que pasó de mueble contenedor a mueble de prestigio social. Es una tipología escasa en la documentación de la primera mitad del siglo XVI, que deriva posiblemente de las arcas, por un lado, y de las arquillas mudéjar, por otro ${ }^{16}$. Su inclusión en los interiores privilegiados españoles de la segunda mitad de siglo era ya muy destacada, realidad que debe interpretarse por un uso de prestigio y posicionamiento social del propietario, más que funcional. Con el

14. Sobre Baldassarre Embriachi y las arquetas de hueso, consultar el catálogo Cofres de amor, Castellón, 2007, y para las arquetas amatorias catalanas, entre otros, las fichas de este tema redactadas por Jaime Barrachina en Moble català, Barcelona, 1994.

15. AGuiLó, El mueble en España, p. 25.

16. AgUiLÓ, El mueble en España, p. 96. 
tiempo, las clases inferiores emularon a las mejor posicionadas, de tal manera que se puede considerar el escritorio como el mueble que mejor define la vivienda española desde 1500 a 1700. A partir de esta última fecha, y por influencia de las nuevas modas borbónicas, el escritorio perdió rápidamente esa consideración preferencial, siendo sustituido por nuevas tipologías que entraron en la casa, principalmente por la cómoda y el buró.

El escritorio responde muy bien a la necesidad de guardar a buen recaudo que, comentábamos, ha experimentado el hombre de todos los tiempos. La estructura organizada por múltiples cajones y compartimentos permitía ordenar todos aquellos objetos pequeños que se necesitaba esconder. En España, solían abrir con una tapa abatible y en los primeros ejemplares se complementaba con otra tapa superior, herencia de las arcas. El uso era privado, al menos en una primera época, y se solía colocar en el estudio, el dormitorio o en otras estancias personales del propietario, pero el diseño estaba pensado igualmente para poderse trasladar con facilidad. Si el señor viajaba este mueble iba consigo, por lo que allá guardaba todo aquello que apreciaba. La concepción de transportable es más relevante en los modelos castellanos, seguramente causado en un primer momento por las necesidades de la corte nómada, y posteriormente, por la permanencia de una constante que había quedado fosilizada. En esos ejemplares pensados para viajar, el exterior no solía lucir gran decoración, en los laterales de la caja se sujetaban fuertes asideros y en las esquinas se colocaban cantoneras de hierro. Los artesanos, además, idearon unos pies ligeros que se desmontaban con facilidad y se podían transportar junto al escritorio. Como en otros muebles españoles de la época, los tornillos pasantes fueron la clave para permitir la mudanza y el montaje de forma fácil. Los cajones y los compartimentos quedaban trabados por la tapa que disponía de un gran escudo de cerradura central y los correspondientes pestillos de seguridad. Ésta fijaba y protegía el interior, de tal manera que el mueble cerrado era una caja de madera resistente y segura que podía, igual que las arcas, ser trasladada cuando fuera menester. La documentación los recoge una y otra vez y en su interior se descubren objetos de lo más variado, principalmente monedas, joyas, objetos de plata, libros, medallas, cera y documentación familiar.

Si quien disfrutaba de un escritorio era alguien que, por un lado sabía leer, y por otro, poseía cosas de valor, estas realidades permiten entender porqué en seguida el contenedor se convirtió en un mueble de carácter simbólico y no únicamente una pieza para guardar más o menos pequeños tesoros. Lo privado se hacía público entre aquellos a los que se les daba acceso al interior de la vivienda. Este uso social revirtió en éxito comercial y en su abrumadora presencia en las viviendas españolas.

La evolución del escritorio es rápida y pronto la organización de los cajones se realizó a partir de una puerta central, que a su vez escondía cajones interiores. Para un intruso que encontrara el mueble cerrado, acceder a esas pequeñas gavetas suponía superar dos barreras: la cerradura exterior del mueble y la de esa puerta interior que daba paso a los escondrijos. Ya a finales del siglo XVI algunas de esas capillas centrales se desarrollaron a la manera de portadas de edificios, haciendo uso de elementos como columnas, tímpanos o balaustradas a partir de unos patrones que derivaban de 
los tratados de arquitectura. Como su permanencia en la casa se alargó y su coste era alto, era posible modernizar ejemplares desfasados o enriquecer los regalados que no convencían. Así en 1592, se añadieron tres pirámides de ébano rematadas por esmeraldas a un escritorio de las manufacturas florentinas regalado a la infanta Isabel Clara Eugenia ${ }^{17}$.

Diferentes centros europeos se especializaron en construir escritorios con técnicas que incidían en su valoración como objeto suntuoso, convirtiéndolo en motivo de deseo entre las clases altas y los dirigentes políticos. Amberes, Augsburgo, Florencia, Milán o Nápoles son algunos de los mejores productores que destacaron por poner en el mercado escritorios de lujo de primera calidad. Si la propuesta tenía éxito, se presentaba a personalidades influyentes y se explotaba comercialmente. Se ha estudiado bien el papel de los escritorios como regalo diplomático, igual que el interesante comercio entre centros ${ }^{18}$.

El hecho de que Felipe II apreciara realmente los escritorios y pasara con ellos largas horas ${ }^{19}$, debió ayudar a difundir el interés de esa tipología de mueble por el territorio y a su buena consideración como obra artística. El interés de Felipe II por estos muebles dinamizó su importación hacia España siendo la nobleza, a imitación de la realeza, la gran clienta. Los modelos circulaban y se copiaban unos a otros, especialmente cuando la técnica era fácil de trabajar, de ahí las dificultades a la hora de detallar la procedencia de algunos ejemplares. En cambio, otras técnicas muy especializadas y difíciles de producir, como la pietra dura de Florencia y Roma, se convertían en sello de un centro determinado que generaba un sólido negocio.

Unas descripciones de 1585 realizadas por el duque de Urbino en España y por Pedro de Mendoza pueden servir de ejemplo de la riqueza de los muebles y de la complejidad del traslado de estas valiosas obras de arte

«Luis Dovara ha traido diversos regalos y uno que ha enviado el Gran Duque [de Toscana] a Su majestad [Felipe II] que afirman que es bellísimo y riquísimo. Es un escritorio de ébano todo guarnecido de oro y de muchas joyas, el cual yo no he visto, pero dicen que vale 25 o 30 mil escudos» ${ }^{20}$.

"Los escritorios que embia el gran duque a v.m.d se han embarcado y acommodado muy bien en las galeras q lleva don Juan de Cardona y la mesa del Car.l Alexandrino la llevo como tengo escrito a V. M.d el capitan nazache en su nave, q debe de haver llegado ya en Alicante o Cartagena $»^{21}$.

17. Perez de Tudela, A., «Los muebles de la colección de Felipe II y de su hija la infanta Isabel Clara Eugenia», en El culto al objeto: de la vida cotidiana a la colección, Barcelona, 2009, p. 48.

18. AguiLÓ, M. P., «Relaciones entre España e Italia en el siglo XVII. La importación de objetos de lujo», en El moble del segle XVII a Catalunya i la seva relació amb altres centres europeus, 2007, pp. 37-47. También Aguiló, M. P., «La exaltación de un reino: Nápoles y el mobiliario de lujo a la vuelta del siglo XVI», en Archivo Español de Arte (258), 1992, pp. 172-179.

19. Perez de Tudela, A., «Los muebles de la colección de Felipe II», p. 48.

20. Perez de Tudela, A., «Los muebles de la colección de Felipe II», p. 48.

21. Ibidem, p. 55. 
Si comentábamos el interés de Felipe II por los escritorios, también debemos subrayar su fascinación por el mobiliario procedente de Augsburgo, de una calidad inigualable. La producción alemana era incomparablemente mejor que la española y el rey, amante de las obras de arte, admiraba sus manufacturas. En sus inventarios se describen multitud de escritorios de esa procedencia, algunos trabajados en marquetería de maderas, denominada en la época «madera de aguas de Alemania» ${ }^{22}$, siendo especialmente valorados los del prestigioso «maestro de hacer escritorios» Bartolomé Weisshaupt, quien llegó a trasladarse a España ${ }^{23}$. Otro gran número de los que compró o recibió como presente estaban decorados en ébano y en plata, y es que el ébano se convierte sin lugar a dudas en la madera preferente para los muebles de lujo desde finales del siglo XVI y durante toda la centuria siguiente, y la plata, como es bien sabido, deslumbraba a los españoles abusando de ella. El color negro de esa madera exótica fue apreciado por diversas razones, por un lado permitía el contraste cromático con cualquier otro material con el que se combinara, ya fuera plata, marfil, piedras semipreciosas, pintura, bronce o concha, favoreciendo los claroscuros y juegos de color agresivos que tanto gustaron en el barroco. Por otro lado, el ébano es una especie densa, de poros muy cerrados, lo que ofrecía acabados muy pulidos, casi perfectos, a diferencia de las imitaciones tintadas. Además, aseguraba una mayor durabilidad de la obra, al ser una madera que resiste al ataque de xilófagos.

De esta manera, el escritorio había subrayando su presencia, se había hecho más visible, más artístico y había pasado a formar parte de los muebles de aparato. En el momento en que el escritorio, enriquecido con técnicas costosas, se exhibía más que se usaba, se desarrollaron cambios en la estructura y disposición. Si en una primera etapa se colocaban sobre mesas, armarios bajos -denominados pie cerrado- o soportes desmontables - citados como pie abierto- ya, a finales de siglo XVI, empezaban a descansar sobre elegantes mesas diseñadas a juego, composición que permaneció hasta el final de su uso, poco después de 1700. Como era de suponer, y ya que el mueble había perdido la necesidad de ser transportable, a menudo se le retiró la austera tapa que impedía la visión del frente de cajones. En caso de ser necesario el traslado, se envolvía el escritorio con fundas y se protegía en una caja de madera realizada a medida, como las que registran los inventarios.

A medida que avanzó el tiempo, el número de ejemplares aumentó considerablemente y no sólo muchas casas tenían escritorio, sino que un buen número lucía una pareja y las mejores contaban con muchos y de diferentes tipos. Se colocaban simétricamente en las salas o galerías, y se acompañaban de asientos arrimados a la pared, de espejos con marcos de ébano y de tapices o pinturas. En 1627, Don Juan de Fonseca disponía de doce escritorios ricos, de los cuales ocho eran de ébano y marfil, y por ello tenía igualmente bufetes de ébano y marfil, además de otros dos escritorios decorados con piedras de vidrio y dos más de Alemania. Estos contenedores se complementaban

22. AguiLó, M. A., «Intarsia y marquetería en el Renacimiento: Italia y Alemania», Madrid, 2004.

23. Perez De Tudela, A., «Los muebles de la colección de Felipe II», p. 48. 
con arquetas o escritorillos que se situaban encima suyo, a la manera de pirámides decorativas

«Los escritorios colocados en parejas o grupos, y mejor aún si encima de ellos se disponen arquetas o escritorillos más pequeños "dos caxas compañeras para sobre escritorio" ${ }^{24}$,

así como urnas y jarros, ramilletes y otros objetos decorativos. En la segunda mitad de siglo XVII muchos escritorios de ebanistería se enriquecieron con elementos y remates decorativos que sobresalían de la caja prismática. Balaustradas, áticos, patas en forma de garra de águila o pequeñas pinturas sobre óleo o tabla colaboraban en crear el aspecto suntuario de las salas donde se exhibían. Definitivamente se abandonaba la relación con el contenedor para el transporte. El 15 de diciembre de 1679, después de visitar el palacio del Retiro, la marquesa de Villars, esposa del embajador francés, escribe a la señora Coulanges

«La galería es bastante larga, tapizada de damasco bermejo, recargado de trecho en trecho por anchas franjas de oro. Desde un extremo a otro hay la más bella alfombra que jamás se haya visto; mesas, escritorios y braseros; sobre las mesas candelabros; y de tiempo en tiempo vense a las meninas, muy adornadas, que entran con dos candelabros de plata para cambiar cuando es preciso, y despabilar las bujías» ${ }^{25}$

En España durante el siglo XVII se realizaron modelos propios, la mayoría de ensambladuría, y también se copiaron ejemplares de ebanistería que se inspiraban en los de otras procedencias, principalmente en los de centros de la Península italiana, como los recubiertos de concha de tortuga o los que se decoraron con placas de hueso o de marfil grabadas. Además, talleres secundarios ofrecían versiones más simples, chapeadas con materiales asequibles. Encontramos que en escritorios de diferentes lugares del territorio español, el carey fue subtituido por palisandro, el ébano por madera ebonizada o por nogal, y en modelos donde debería lucir el marfil, lo hacían las más económicas placas de hueso ${ }^{26}$.

A pesar de la crisis del período y de que muy pocos ejemplares han llegado hasta nosotros, la documentación nos descubre que las casas de alto rango españolas del siglo XVII lucían muebles de lujo, que en su gran mayoría llegaban del extranjero y muchos de ellos se forraban de materiales $\operatorname{caros}^{27}$. De esta manera, el artesano especializado en la construcción de estos valorados escritorios y demás muebles realizados con maderas exóticas, especialmente con el costoso ébano, empezó a gozar de una consideración social superior a la del resto de los carpinteros o ensambladores, lo que

24. AguiLÓ, M. P., El mueble en España, p. 22.

25. Garcia Mercadal, J.,»Los marqueses de Villars», Viajes de extranjeros por España y Portugal, vol. III, p. 674.

26. Diversas colecciones públicas y privadas guardan ejemplares de escritorios españoles, entre ellas el Museo Nacional de Artes Decorativas y el Museu de les Arts Decoratives de Barcelona.

27. CAstellanos, C., «Breves nociones sobre mobiliario español del siglo XVII», en El moble del segle XVII a Catalunya i la seva relació amb altres centres europeus, 2007, pp. 83-90. 
permitió distinguirlo y ser conocido bajo el nombre de ebanista ${ }^{28}$. Así, no sorprende que Jerónimo de Villanueva, encargado en adquirir obras para Felipe IV, regalara personalmente tapicerías, espejos, cristalerías y, en compañía de la Junta de Obras y Bosques, un escritorio de ébano y marfil con columnillas de cristal y figuritas de plata y oro, valorado en 30.000 ducados ${ }^{29}$, que procedía de importación.

En algunos ejemplares españoles, cuando el escritorio se diseñaba con la portada arquitectónica central, los compartimentos secretos no se presentaban como escondrijos detrás de los cajones o como huecos entre la caja y éstos, sino que se ofrecían, al que intentara descubrirlos, de forma mucho más ingeniosa. En realidad, algunas de las columnas, pilastras o frontones que decoraban el frontis, eran escondites en sí mismos, a la vista de todos y sin llaves de seguridad, pero pasando desapercibidos bajo la apariencia de esas formas arquitectónicas. Cuando ahora, en el siglo XXI, nos atrevemos a enfrentarnos a uno de estos muebles e intentamos comprender su organización y saber por dónde abre y cuántos cajones tiene, nos damos cuenta que el artesano que lo construyó planteó un reto al ususario, un juego que se mantiene vivo a día de hoy, cuatro siglos más tarde. Saber cuáles son los elementos fijos y cuáles los que abren no era y no es tarea fácil a no ser que estemos dipuestos a tocar y fallar, es decir a experimentar. Es en ese momento, que entendemos el valor real del escritorio en la Edad Moderna. Era mucho más que un mueble de seguridad, que un contenedor de bienes caros, era mucho más que un mueble recubierto por técnicas y materiales exquisitos y técnicas costosas, los mejores eran en sí mismos un artefacto intelectual.

El escritorio penetró en la clase burguesa, incluso de provincias, y se desarrollaron tipos propios en cada zona, que mantenían las técnicas decorativas que eran habituales en otros muebles del lugar. Así, por ejemplo, centros de la Corona de Aragón que en el siglo XVI trabajaban muebles con pequeñas piezas de embutido de hueso y filetes de boj por influencia mudéjar, desarrollaron escritorios con esa misma decoración ${ }^{30}$.

28. El término ebanista empieza a ser utilizado en algunas ciudades en este momento de prestigio del ébano y del escritorio. En los diferentes idiomas, se nombra a este especialista a partir de una de esas dos palabras, por ejemplo ébéniste en francés, cabinetmaker en inglés. Normalmente formaban parte del mismo gremio que los ensambladores, pero en la práctica realizaban otro tipo de trabajos. En Cataluña no había esta diferenciación y todos los artesanos del mueble formaban parte del gremio bajo el nombre de fuster. En todo caso, el término ebanista se utilizaba para referirse a algún maestro de otros lugares de España o del extranjero. Sobre el caso catalán, consultar PIERA, M., «El comercio de muebles en Cataluña durante el siglo XVIII», en Dialectología y tradiciones populares, vol 66, 2011, pp.109-138 y PIERA, M., «Muebles de ebanistería en las viviendas de Barcelona», en El mueble del siglo XVIII: nuevas aportaciones a su estudio, 2009, pp. 63 a 74.

29. Aguiló, M. P., El mueble en España, p. 18.

30. La documentación catalana se refiere a esta técnica como tercia o tarsia, derivando directamente del término árabe, que igualmente se utiliza en italiano. Actualmente se conoce la técnica bajo el término de pinyonet o pinyolet, haciendo referencia a la forma de las piezas de hueso (piñones en el primer caso, piñuelos en el segundo). Sobre un taller importante de Barcelona, dedicado a la producción de muebles, entre los que se citan un buen número decorado con esta técnica de embutido de hueso y boj, se puede consultar PIERA, M., «El mueble en la documentación de Barcelona en el siglo XVII. El inventario y la almoneda de los bienes del carpintero Lluís Massot de 1608 y el inventario de Joan Francesc 
En Asturias, en cambio, se diseñaron escritorios con embutido de diferentes maderas que dibujan estilizaciones vegetales, leones y escudos de grandes proporciones enmarcados en cenefas de eslabones, igual que se realizaba con las alacenas y las $\operatorname{arcas}^{31}$. A menudo, y especialmente dirigidos para la clase media se propusieron tipologías de mueble combinadas, de tal manera que en una sola estructura se superponía un armario, un escritorio y una alacena, recordándonos una vez más que el mobiliario era caro, que la multifuncionalidad seguía vigente en la Edad Moderna y además que el mueble se colocaba con seguridad en la sala y ya no en las estancias privadas.

Llegados al siglo XVIII, el escritorio pierde rápidamente protagonismo. El modelo de interior francés que entra de la mano de la dinastía borbónica se extendió por el territorio español con una nueva propuesta de organización de los espacios. Originales muebles tomaron el lugar principal de las salas, siendo la cómoda y sus derivados los preferidos. Aún así, el hombre de la Ilustración siguió necesitando contenedores donde guardar objetos de valor. Muebles que incluían secretos que alejaban algunas pertenencias de la vista pública. Sin grandes innovaciones con respecto a períodos anteriores, los carpinteros desarrollaron nuevamente falsos fondos y compartimentos ocultos por detrás de las gavetas. También aprovecharon los huecos que generaban las estructuras curvadas del estilo rococó para idear escondrijos. De todas las tipologías donde se practicaron, destacan las cómodas, los armario guarda-robas y, sobre todo, los nuevos escritorios, que actualmente llamamos burós, pensados para guardar los papeles y el dinero. Aun así, el éxito de la ocultación no siempre estaba garantizado, ya que era el primer lugar a buscar si se producía un robo, como bien explica el barón de Maldá

«Los lladres continuen encara sos robos per Barcelona; i lo pitjor d'esos malfactors és tenir certs ferros ab què obren totes les portes i demés cerraduras de calaixos d'escriptoris i calaixeres, àdhuc lo més recòndit, que són los secrets de la moneda. [...] I ab lo xasco terrible, los amos, de veure's de repente pobres pelats» ${ }^{32}$.

\section{LOS ESCRITORIOS DE AUGSBURGO, GABINETES DE CURIOSIDADES}

Recuperando el hilo de los escritorios europeos de los siglos XVI y XVII, los ebanistas de Augsburgo sobresalieron en la producción de muebles de lujo. Crearon piezas de gran pericia que se conocían bajo el nombre de Kabinettschränke, y se exponían en los gabinetes de curiosidades junto a otras grandes obras naturales y artificiales. Ya en el siglo XVI, la ciudad imperial libre tuvo una reputación excelente como centro productor de objetos artísticos con un nivel de perfección altísimo que permitió generar un mercado activo para una selecta clientela. En la segunda mitad de siglo XVI destacó la manufactura de escritorios decorados en marquetería de maderas locales que cubrían

Pratnarbona de 1688», en El moble del segle XVII a Catalunya i la seva relació amb altres centres europeus, Barcelona, 2007.

31. Sobre el mueble en Asturias, consultar DIAZ, G., «El arca en el mobiliario de la Asturias preindustrial: piezas del concejo de Grado», en Revista de Dialectologia y Tradiciones Populares, vol. LXVI, 2011, pp.13-46.

32. Amat, R., Calaix de Sastre, Barcelona, 1987, vol VII, p. 15. 
toda la superficie visible del mueble. Normalmente abrían por puertas ricamente trabajadas por dentro y por fuera, así como los frentes de los cajones. La marquetería, que combinaba chapas de maderas diversas, se organizaba en dibujos complejos de gusto manierista, siguiendo grabados de artistas alemanes del momento. La obra más formidable de este tipo que ha llegado hasta nosotros es el Wrangelschrank, realizado en Augsburgo y datado en 1566 pero del que se desconoce el autor ${ }^{33}$. Su prodigioso trabajo fue referencia para otros escritorios de menor calidad que se construyeron en Augsburgo y en Nuremberg en aquel período. Los interiores de estos muebles recogen una sucesión de cajones y puertas que esconden otros compartimentos interiores. Algunos de los cuerpos salen enteramente y es al retirarlos de la estructura del mueble que se descubren nuevos huecos más pequeños delicadamente trabajados. Secretos y más secretos cuya localización exige observación y para abrirlos meticulosidad y paciencia.

Las puertas de paso de El Escorial realizadas para Felipe II por Bartolomé Weisshaupt a partir de grabados de Hans Vredeman de Vries $^{34}$, son la otra gran obra de esos talleres de marquetería alemanes y una demostración más de la fama de esa producción. Como hemos comentado, Felipe II apreciaba enormemente esa técnica realizada a partir del encolado de finas chapas sobre el macizo que se combinaban a partir de dibujos complejos de ruinas y paisajes. Además de las puertas, el rey encargó muchos otros muebles, difundiendo los escritorios manieristas de marquetería entre la nobleza española, alumbrada por el prodigioso trabajo.

Fue a finales de siglo XVI cuando en estos centros germánicos las labores de taracea dejan paso a las piezas forradas de ébano y también de marfil entre otros materiales exóticos. De 1610 a 1655, por ejemplo, la corte de Baviera encargó una serie de cajas de farmacia, arquetas, baúles y cabinets realizados en piedras preciosas, nácar, concha y marfil. Una industria de lujo que daba trabajo a un gran número de artesanos, y también activaba la gestión de los bancos y de los agentes comerciales. Los altos precios de estas piezas obligaron a regular el uso de los metales y a asegurar, por ejemplo, que fuera oro y plata de suficiente pureza lo que se utilizaba en los talleres de orfebrería. Esa norma era de estricto cumplimiento ya que de ella dependía una industria poderosa, que en el año 1600 daba trabajo a unos 200 maestros de la ciudad y vendía a todo el continente ${ }^{35}$. Igualmente, el gremio de ebanistas obligó a marcar los muebles con el símbolo de la ciudad, una piña, y la de la madera, eben, para certificar que efectivamente se utilizaba ébano y no imitaciones tintadas, que se ofrecían en el mercado ilegal y podían afectar a la reputación de las manufacturas de la ciudad.

33. Actualmente se conserva en el Landesmuseum für Kunst und Kulturgeschichte en Münster. El exterior de la caja y el interior de las puertas están totalmente recubiertas de marquetería mientras que los frentes de los cajones están tallados con escenas militares en boj, separadas por columnas de alabastro. El mueble es un magnífico ejemplo de el arte de la carpintería alemana al servicio de las clases dirigentes.

34. AGuiló, M.A., Intarsia y marquetería, p. 8.

35. AlfTER, D., «Marked Augsburg furniture. A warranty seal for provenance and quality», en Furniture for European Kunstkammer, Munich, 2008. 
Como evolución de los modelos que se venían realizando, entre las propuestas de Ausburgo empezó a desarrollarse la idea de generar cabinets que se podían vender con el contenido interior. Ya no era el señor que compraba el mueble contenedor donde guardar sus bienes de valor; sino que el artista le ofrecía objetos que podían ser de su interés y que vendía conjuntamente a la caja. Era la propuesta de un mueble completo donde contenido y continente desarrollaban una obra de arte total.

Comentábamos que en la Europa de finales del Renacimiento, el escritorio utilitario pasaba a escritorio de representación, pero en Alemania se daba un paso más, y el mueble se erigía como un pequeño gabinete de maravillas, donde los secretos ayudaban a adquirir conocimiento. La intención era ofrecer un cabinet o escritorio como espejo del macrocosmos, donde el mueble era el cosmos y en su interior, de forma ordenada el propietario iría descubriendo los tesoros de la naturaleza, tanto los de Naturalia como los de Artificialia, lo que convertía el conjunto en una colección enciclopédica ${ }^{36}$. Se trataba de un Kunstkammer en miniatura, pensado para las élites intelectuales. Los escritorios recogían ordenadamente las maravillas del universo, así como exquisiteces culturales y colecciones en miniatura, una idea que se adaptaba muy bien a una clientela interesada en conocer y en mostrar su conocimiento ${ }^{37}$.

Comúnmente, estos nuevos escritorios se decoraban con imágenes que representaban el orden divino y el lugar del hombre en el universo. Ya fuera en taracea, en grabado sobre marfil o en metal o pintados sobre cobre o tabla, se mostraban los cuatro elementos, los siete planetas, las estaciones, los doce símbolos del zodíaco o los doce meses. Otros temas habituales en estas obras, que incidían en la idea de ordenación y clasificación, eran la representación de las artes liberales y las mecánicas, o las virtudes y los vicios.

Estas temáticas acompañaban los objetos que se guardaban en el escritorio, que a su vez debían presentarse de manera inteligente en consonancia con este homenaje a la sabiduría en que se había convertido el mueble. Por ello, la propuesta debía ser no sólo original, sino que debía despertar interés y curiosidad, y dejar testimonio del ingenio del creador y, sobre todo, del propietario. No se trataba entonces de construir, por ejemplo, una vitrina expositiva, sino de guardar los tesoros en gavetas y compartimentos escondidos, que el espectador convertido en usuario, debía ir descubriendo a medida que los accionaba. Sólo quien tuviera paciencia, suficiente inteligencia y astucia sería capaz de llegar al final de la experiencia.

El interés no radicaba únicamente en la riqueza de los materiales utilizados para construir el escritorio ni en extraordinaria calidad de la decoración, ni en la forma de resolver la temáticas representadas, ni siquiera en la selección de objetos escogidos para colocar en su interior, realizados muchos en plata, sino especialmente en la creativa dis-

36. INIESTA, M., Els gabinets del món. Antropologia, museus i museologies, Lleida, 1994. CAMPI, I., «El surtido de objetos: del museo al supermercado», en El culto al objeto: de la vida cotidiana a la colección, Barcelona, 2009.

37. SPENLÉ, V. «The cabinet and its importance to Kunstkammer and Wunderkammer in the 17th century», en Furniture for European Kunstkammer, Munich, 2008. 
posición de los mismos que obligaba al usuario a superar el reto planteado por el artista. Efectivamente, bajo una estructura sencilla a simple vista, se le presentaba una realidad compleja, que debía comprender y solucionar. Es así que los cabinetes alemanes llevaron mucho más lejos la propuesta de divertimento intelectual que comentábamos con respecto a algunos escritorios españoles. En Augsburgo, por tanto, el reto era mucho mayor que cualquier otro mueble con secretos. No era esconder para custodiar, era esconder para ejercitarse de la mano de una obra exquisita en todos los sentidos. La idea partía de que el escritorio se debía admirar, pero sobre todo usar y aprender de él y con él. Una propuesta artística donde la sorpresa por el descubrimiento llegaba a su máxima expresión.

El primer paso imprescindible para poder acceder al cabinet o artefacto intelectual, era la meditación y la contemplación atenta y tranquila, pasos también considerados necesarios para avanzar en el conocimiento. Si se analizaba y se razonaba bien se podía empezar a experiementar, es decir, a participar. Se iniciaba así un diálogo con el mueble que iba subiendo de intensidad a medida que se exploraba. Superada una prueba, la observación y análisis de uno de los objetos, se iniciaba el reto de encontrar el siguiente y estudiarlo, cosa que permitía establecer relaciones con las demás partes. Estos mismos pasos los planteaba el dueño a sus selectos invitados con quienes deseaba compartir su experiencia.

En el momento que se consiguió que el escritorio pasara de ser un mueble para guardar objetos de valor, a un mueble que aportaba conocimiento a través de la experiencia, su prestigio llegó al máximo apogeo y su desarrollo entre las cortes y entre las clases dirigentes fue rápido. Hacia 1570-1580 el escritorio de ébano y plata de Augsburgo había llegado a su madurez.

La obra de referencia y principal exponente del escritorio intelectual elaborado en Augsburgo fue el famoso Pommersche Kabinettschrank realizado para Felipe II, duque de Pomerania-Stettin y su mujer. El agente artístico que dirigió el encargo fue Philip Hainhofer, hombre de gran cultura y coleccionista que jugó un papel decisivo en la difusión y comercialización de obras de arte de esta ciudad entre las élites europeas. En realidad, se trataba del primer encargo que había recibido de un cliente de fuera de la ciudad, por lo que Hainhofer estaba muy interesado en conseguir un resultado sonado. Se carteó con el duque hasta convencerle que se quedara una obra mucho más importante que la que él inicialmente había pedido, una pequeña escribanía. Los argumentos para ello se basaban en la necesidad de disponer de un mueble relevante, apropiado a un hombre de su rango y poder, que recogiera su saber y lo mostrara en público. Hainhofer, que tenía su propio gabinete de curiosidades, sabía los beneficios sociales que representaba ese espacio de la cultura, y por ello tenía argumentos sólidos para convencer a éste y los demás clientes.

Los objetivos se cumplieron con creces y podemos considerar el escritorio de Pomerania, como una obra de arte total y uno de los más importantes muebles de la historia. Se inició en 1610 y no fue terminado hasta 1617. En su construcción participaron veinticuatro maestros de quince especialidades, siendo el ebanista principal Ulrich Baumgartner. Siete intensos años de trabajo para diseñar y acabar un escritorio de ébano que podía ser contemplado por las cuatro caras y que sintetizaba todas las ramas 
del conocimiento humano. Con una estructura de templete se decoró con escenas que representaban las artes liberales y el conjunto se culminaba con figuras de musas. El duque descubriría en el interior elegantes objetos, como un tablero de ajedrez y otros juegos de mesa de plata, objetos de escritorio, de tocador, instrumentos científicos, de medicina y de barbero, instrumentos matemáticos de gran interés en la época y objetos multifuncionales como hueveras que podían servir de incensarios o un telescopio que se convertía en instrumento de cirujano. Se escondían un total de trescientas piezas, que respondían a los mejores ejemplos del artificio y que reflejarían los intereses del propietario. Este mueble sobresalió entre todos los escritorios conocidos de Augsburgo y a pesar de haberse perdido en la Segunda Guerra Mundial, la cantidad de información disponible sobre él es elevada, con una descripción contemporánea a la obra que detalla el contenido, así como fotografías en blanco y negro de antes de su pérdida, lo que permite valorar su excepcionalidad ${ }^{38}$. De todo el conjunto únicamente se conservan partes de su contenido, como el magnífico tablero de ajedrez, o los datos que en su interior dejaban constancia del comitente, el agente comercial y el autor. Incluso se conserva una pintura de Anton Mozart que recoge la entrega del escritorio al duque Felipe II de Pomerania ${ }^{39}$. En realidad debía ser una propuesta para ese acontecimiento, ya que se pintó en 1615, dos años antes de haberse acabado el mueble. Aunque la pintura no tiene una gran calidad técnica es un muy buen documento de lo que se esperaba de esa gran cita. Se representa el fantástico mueble abierto sobre una mesa del que salen los objetos curiosos. Los duques, rodeados por su séquito, se muestran atentos a los contenidos que Hainhofer y Baumgartner les presentan en uno de los cajones que han extraído del mueble. Finalmente los artesanos que trabajaron en el proyecto, y que se colocan en procesión, llevaban en sus manos las diferentes creaciones que formaban parte del contenido enciclopédico para mostrarlas al comitente.

Que la propuesta de estos magníficos muebles con secretos tenía un componente lúdico y ofrecía diversión a través del conocimiento, queda subrayada en la frase que el gran maestro de los cabinets de Augsburgo escribe con orgullo en el más recóndito escondrijo de su espléndido escritorio de Pomerania

«Ulrich Baumgartner Kistler Ao 1615 ehe veracht als gemacht»

que podemos traducir como «Ulrich Baumgartner, ebanista en 1615. Más fácil de criticar que de crear». Un premio que sólo leía quien llegara a alcanzar esa última pieza del rompezabezas y una sentencia que revelaba el orgullo de la creatividad.

38. Las fotografías se publicaron en el trabajo publicado por LESSING, J. i BRÜNING, A., Der Pommersche Kunstschrank, Berlin, 1905. De los muchos trabajos sobre este escritorio, es de interés el de MuNDT, B., «Der Pommersche Kunstschrank«, en Möbel für die Kunstkammern Europas, Munich, 2008. El mueble pasó a los Electores de Brandenburgo y al morir el último descendiente de la familia ducal Pomeral en 1684 se trasladó al Kunstgewerbemuseum en Berlin. Desgraciadamente, se destruyó a causa de una bomba estando depositado en el museo de artes decorativas de la ciudad. Hasta 1945 el mueble se encontraba completo, cosa que no sucedía con otros interesantes escritorios también entregados por Hainhofer a diferentes clientes, de los cuales la mayoría han perdido el contenido.

39. Actualmente esta tabla pintada se conserva en el Kunstgewerbemuseum de Berlin. 
Si este escritorio marca un hito en la historia de los ejemplares augburgueses y se convirtió en prototipo de los modelos realizados en ébano, veinte años más tarde los talleres de la ciudad se decantan por forrar de marfil esas pequeñas cajas de conocimiento, siendo el hijo de Ulrich, Melchor, uno de los más destacados creadores en este campo. De todas formas, a partir de la Guerra de los Treinta Años la ciudad inicia una decadencia sin retorno, dejando paso a otros centros en esa competencia por el mercado del arte al servicio de las élites. Amberes, Roma y sobre todo París se convirtieron en los creadores de nuevas experiencias artísticas que saciaron el ansia de conocimiento y la pasión por la creatividad.

Además, los gabinetes de curiosidades, tanto de habitaciones completas como de escritorios, que recogían y equiparaban las maravillas divinas con las humanas, fueron dejando paso a nuevos modelos de clasificación regidos por criterios más científicos. Sin vuelta atrás, se separó la Naturalia de la Artificialia, y se desarrolló el concepto de colección especializada. Paralelamente se empezó a cuestionar el hecho de que estos espacios del saber estuvieran cerrados y fueran accesibles únicamente a unos pocos. En su contra, se propusieron colecciones que permitieran que la cultura se abriera al mundo. A partir de esa nueva etapa, los objetos se exhiben y se dejan a la vista de los interesados, para lo cual se utilizó un mueble ideal, la vitrina, que con sus láminas de vidrio plano permitía observar de cerca, pero no tocar. Con la vitrina mueren, por tanto, esos escritorios que escondían el conocimiento dentro de sus secretos y que para alcanzarlo obligaban a experimentar, muebles que magistralmente había desarrollado la ciudad de Augsburgo. 